\title{
Identification of Odorous Compounds in Fresh and Rotten Swine Manure
}

\author{
Akio Yasuhara, Keiichiro Fuwa and Masayuki JiMBU* \\ Chemistry and Physics Division, National Institute for Environmental Studies, \\ Yatabe, Tsukuba-gun, Ibaraki 305, Japan \\ *Department of Animal Genetics, National Institute of Animal Industry, \\ Kukizaki, Inashiki-gun, Ibaraki 305, Japan
}

Received April 24, 1984

\begin{abstract}
In order to elucidate the nature of malodor from piggery wastes, volatile compounds in fresh faeces, fresh urine, rotten urine, and rotten mixtures of faeces and urine were isolated by freeze vacuum distillation and continuous extraction and identified by gas chromatography-mass spectrometry. Many alcohols were detected not in fresh urine, but in faeces. Various fatty acids were determined at high concentrations in all samples, but their abundance was different in faeces and urine. Large amounts of phenols came from urine. Aromatic carboxylic acids were detected only in urine and decreased rapidly during digestion. Indole and 3-methylindole which were present only in faeces showed a reverse change of concentration during digestion.
\end{abstract}

The level of odor nuisance in Japan has been the highest except for noise nuisance ${ }^{1)}$ for ten years. Complaints about the animal industry are a large proportion of the total number of complaints, since animal farms are located near residential districts. Hog houses are one of the main sources of odor pollution as well as poultry houses. Japanese acts regulate atmospheric concentrations of eight odorous compounds such as ammonia and hydrogen sulfide, but the regulations are not effective for odor control of the livestock industry. ${ }^{2)}$ The probable reason is that some other compounds contribute largely to the malodor. Therefore, investigation of odorous compounds evolved from hog houses has been carried out over a period of eight years by the authors. The general concept of the research method for odors has been described in a review. ${ }^{3)}$

This article deals with malodor from swine farms. Swine manure is the most important source evolving malodor among manure, feed, body, and the house itself. ${ }^{4)}$ This presumption that malodor is mainly due to swine manure agrees with the observation that odorous components in the atmosphere over manure are almost the same as those in manure. ${ }^{5)}$ Lots of work on identification of odorous compounds has been concerned with the atmosphere in pig houses. ${ }^{6 \sim 12)}$ The most important analytical method is gas chromatography. Some analytical methods are described in a review. ${ }^{13)}$ Dust in pig houses has been analyzed by Hammond et al. ${ }^{14,15)}$ While, a lot of concern has been paid to swine manure which is composed of urine and faeces. Steam distillation ${ }^{9,16,17)}$ or solvent extraction $^{4,18,19)}$ was used for isolation of organic compounds from manure. Recently it has been reported that freeze vacuum distillation which is high vacuum distillation while freezing the sample is the most useful method in these cases. $^{20 \sim 22)}$ Volatile compounds in samples having high water content can be isolated efficiently by this vacuum distillation. ${ }^{23,24)}$

In this article, identification and behavior of odorous compounds in fresh swine urine, fresh faeces, rotten urine, and rotten mixtures of urine and faeces are described.

\section{MATERIALS AND METHODS}

Sampling of swine manure. Fresh swine urine and faeces were gathered separately within 8 hours after excretion in 
the National Institute of Animal Industry on July 14 to July 17, 1982 from 4 or 5 pigs which were between 4 and 5 months old, first generation crosses between Landrace and Hampshire, and were fed on a normal diet prepared by the National Institute of Animal Industry. In order to average dispersion of concentrations of volatile components in each sample, the following procedures were used. Fresh faeces and urine from several pigs were united and mixed well, respectively, as soon as possible after sampling. Faeces or urine were divided into several parts as shown in Table I. Each part was put into a flask (volume, 3 liters) and subjected to each conditions shown in Table $I$. Samples No. 1 to 5 were cooled rapidly at $-20^{\circ} \mathrm{C}$. Samples No. 6 to 11 were digested under almost anaerobic conditions at room temperature $\left(28 \sim 30^{\circ} \mathrm{C}\right)$ for a week. Then, the rotten samples were frozen rapidly at $-20^{\circ} \mathrm{C}$.

Separation of volatile components. The frozen samples were cooled further to $-80^{\circ} \mathrm{C}$ for more than 12 hours before freeze vacuum distillation. An apparatus for freeze vacuum distillation is shown in the literature. ${ }^{22)}$ The vacuum pressure was kept under $c a .10^{-4}$ Torr. A receiver trap and an oil trap were cooled at -100 and $-195^{\circ} \mathrm{C}$, respectively. The sample flask was kept at room temperature for $1 \mathrm{day}$, heated at $c a .70^{\circ} \mathrm{C}$ in a hot-air bath for the next 1 or 2 days, and then heated to $c a .100^{\circ} \mathrm{C}$ by a mantle heater until no more water and volatiles were collected in the receiver trap. After melting the water-containing volatile compounds were subjected to continuous extraction, using apparatus which has already been reported, ${ }^{22)}$ for $24 \mathrm{hr}$ with diethyl ether, which was redistilled through a Widmer column ( $45 \mathrm{~cm}$ length) immediately before use. The organic layer was separated and dried with anhydrous sodium sulfate. The residue in the sample flask was mixed with diethyl ether, which was similarly redistilled, and the remaining compounds were eluted for $24 \mathrm{hr}$. The extracted solution was concentrated to $c a .40 \sim 50 \mathrm{ml}$ with a Kuderna-Danish concentrator under atmospheric pressure after filtration. The concentrated solution was distilled under high vacuum ( $c a .10^{-4}$ Torr) and both receiver

Table I. Details of Swine Manure Samples

\begin{tabular}{rrrl}
\hline Sample No. & $\begin{array}{r}\text { Urine } \\
(\mathrm{ml})\end{array}$ & $\begin{array}{c}\text { Faeces } \\
(\mathrm{g})\end{array}$ & $\begin{array}{l}\text { State of } \\
\text { manure }\end{array}$ \\
\hline 1 & 0 & 1000 & Fresh \\
2 & 0 & 662 & Fresh \\
3 & 1000 & 0 & Fresh \\
4 & 1000 & 0 & Fresh \\
5 & 1000 & 0 & Fresh \\
6 & 1000 & 0 & Rotten \\
7 & 1000 & 0 & Rotten \\
8 & 1000 & 0 & Rotten \\
9 & 860 & 228 & Rotten \\
10 & 860 & 228 & Rotten \\
11 & 860 & 228 & Rotten \\
\hline
\end{tabular}

and oil traps were chilled with liquid nitrogen. The distillate was combined with the organic layer described above. The combined solution was concentrated to a few milliliters under atmospheric pressure using a Snyder column ( $20 \mathrm{~cm}$ length).

Analysis of volatile compounds. Identification of volatile components was carried out by gas chromatography-mass spectrometry (GC/MS) using a packed column. Quantification of odorous components was performed by gas chromatography (GC) using a packed column. GC/MS conditions were as follows: Apparatus, a JEOL JMSDX300 mass spectrometer connected with a Hewlett Packard 5710A gas chromatograph and a JEOL JMA3500 mass data analysis syatem; column, 5\% Thermon3000 ( $3 \mathrm{~m} \times 3 \mathrm{~mm}$ i.d.) on Chromosorb W ( $80 \sim 100 \mathrm{mesh})$; column temperature, $50^{\circ} \mathrm{C}$ for $2 \mathrm{~min}$, followed by an increase to $210^{\circ} \mathrm{C}$ at a rate of $4^{\circ} \mathrm{C} / \mathrm{min}$; injection port temperature, $250^{\circ} \mathrm{C}$; helium flow rate, $20 \mathrm{ml} / \mathrm{min}$; enricher temperature, $250^{\circ} \mathrm{C}$; ion-source temperature, $220^{\circ} \mathrm{C}$; ionsource pressure, $2 \times 10^{-6}$ Torr; electron energy, $70 \mathrm{eV}$; ionizing current, $300 \mu \mathrm{A}$; accelerating voltage, $3 \mathrm{kV}$; scan range, $m / z 10$ to 400 ; scan speed, $2.1 \mathrm{~s} / \mathrm{scan}$; repetition time, $2.5 \mathrm{~s}$. GC conditions were the same as above except for the following: Apparatus, a Shimadzu GC-7A gas chromatograph; nitrogen flow rate, $50 \mathrm{ml} / \mathrm{min}$.

The following conditions were used for analysis of trimethylamine: Column, $15 \%$ diglycerol $+5 \%$ tetraethylenepentamine $+2 \% \cdot \mathrm{KOH}$ on Chromosorb W (80 100 mesh), $3 \mathrm{~m} \times 3 \mathrm{~mm}$ i.d.; column temperature, $70^{\circ} \mathrm{C}$; injection port temperature, $120^{\circ} \mathrm{C}$; nitrogen flow rate, $40 \mathrm{ml} / \mathrm{min}$. Analytical procedures were gas bubbling of effluent from a manure sample by gas stripping into dilute sulfuric acid and liberation by addition of alkali solution.

Sensory test. Effluent gas from the gas chromatograph column described above was divided into two streams. One stream was led to a flame ionization detector and the other was vented near the injection port. The investigator sniffed the odor of the vented gas at the same time as peaks were observed on a recorder. The odor of the authentic compound was sniffed in the same way and compared with the odor of extracts from swine manure.

\section{RESULTS AND DISCUSSION}

Recovery of several spiked compounds in freeze vacuum distillation including solvent extraction procedure from the residue is shown in Table II. Recovery of dimethyl disulfide was less satisfactory because of its high volatility. The recovery might be improved by cooling the receiver trap with liquid nitrogen. Ammonia, hydrogen sulfide, and methanethiol are trapped not in a receiver trap but in an oil 
TABle II. Recovery OF OdoROUS COMPOUNDS By Freeze Vacuum Distillation ${ }^{a}$

\begin{tabular}{lr}
\hline \multicolumn{1}{c}{ Compound } & Recovery $^{b}(\%)$ \\
\hline Dimethyl disulfide & 30 \\
Dipropyl sulfide & 86 \\
2-Mehylpropanol & 94 \\
Butanol & 95 \\
3-Methylbutanol & 99 \\
Pentanol & 97 \\
3-Hydroxy-2-butanone & 92 \\
Acetic acid & 79 \\
2-Methylpropanic acid & 94 \\
Butanoic acid & 94 \\
3-Methylbutanoic acid & 96 \\
Pentanoic acid & 95 \\
4-Methylpentanoic acid & 97 \\
Hexanoic acid & 97 \\
Phenol & 102 \\
p-Cresol & 100 \\
p-Ethylphenol & 101 \\
Indole & 97 \\
3-Methylindole & 101
\end{tabular}

a This method includes solvent extraction from distillation residue and vacuum distillation of the extract.

$b$ Average of two runs.

trap. The low recovery of acetic acid was unexplained. Most volatile compounds except for highly volatile compounds and acetic acid have been isolated quantitatively by this distillation method. Recoveries of fatty acids and indoles by this freeze vacuum distillation are higher than those in steam distillation ${ }^{25)}$ and solvent extraction. ${ }^{26,27)}$

Table III shows the amounts of distillates and residues. Water content $(72.6 \%)$ in faeces was consistent with the value reported in a previous study. ${ }^{28)}$ It is very interesting that there is a difference between residual amounts in fresh and rotten urine. Decrease of residual substances, which are almost $30 \%$ based on the value in fresh urine, from $5.4 \%$ in fresh urine to $3.7 \%$ in rotten urine has been considered to be caused by microbial degradation of nonvolatiles into volatile compounds. Similar phenomena were observed in rotten mixtures of urine and faeces. This result is identical with Spoelstra's results ${ }^{29)}$ which show that decrease of nonvolatiles in liquid manure is due to decrease of fiber and protein.
Table III. Amounts of Distillate and Residue in Freeze Vacuum Distillation of Swine Manure

\begin{tabular}{rcccc}
\hline Sample & $\begin{array}{c}\text { Amount } \\
\text { of } \\
\text { distillate } \\
(\mathrm{ml})\end{array}$ & $\begin{array}{c}\text { Amount } \\
\text { of } \\
\text { residue } \\
(\mathrm{g})\end{array}$ & $\begin{array}{c}\text { Ratio } \\
\text { of } \\
\text { volatiles } \\
(\%)\end{array}$ & $\begin{array}{c}\text { Average } \\
\text { ratio of } \\
\text { volatiles } \\
(\%)\end{array}$ \\
\hline 1 & 710 & 282 & 71.8 & 72.6 \\
2 & 470 & 177 & 73.3 & \\
3 & 950 & 54 & 94.6 & \\
4 & 950 & 53 & 94.7 & 94.6 \\
5 & 962 & 54 & 94.6 & \\
6 & 950 & 44 & 95.6 & \\
7 & 950 & 32 & 96.8 & 96.3 \\
8 & 950 & 36 & 96.4 & \\
9 & 980 & 89 & 91.8 & \\
10 & 1000 & 88 & 91.9 & 92.0 \\
11 & 1000 & 84 & 92.3 & \\
\hline
\end{tabular}

Ratio of volatiles is calculated as follows; Ratio of volatiles $(\%)=100 \times($ initial sample weight - residual weight)/initial sample weight.

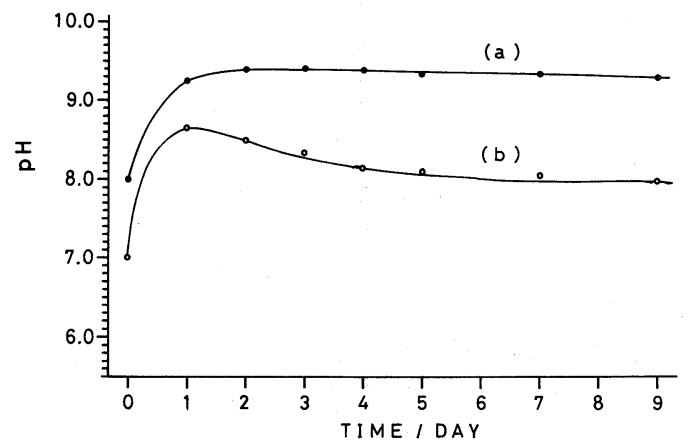

FIG. 1. Changes of $\mathrm{pH}$ Values of Swine Manure during Digestion.

(a): $\bigcirc$, urine. (b): $\bigcirc$, mixture of faeces and urine. Time (day) is counted after date of sampling.

Changes of $\mathrm{pH}$ in urine and mixtures of faeces and urine during digestion are shown in Fig. 1. Rotten urine showed higher $\mathrm{pH}$ than rotten mixtures of urine and faeces. In order to manifest what causes the difference of $\mathrm{pH}$ between the two samples, concentrations of ammonia in the air above a sample in a flask were measured by the indophenol method. Results in two runs were 3,290 and 3,120 ppm (v/v) for rotten urine and 309 and $376 \mathrm{ppm}$ $(\mathrm{v} / \mathrm{v})$ for a rotten mixtures of faeces and urine. Therefore, it is clear that the difference of $\mathrm{pH}$ 


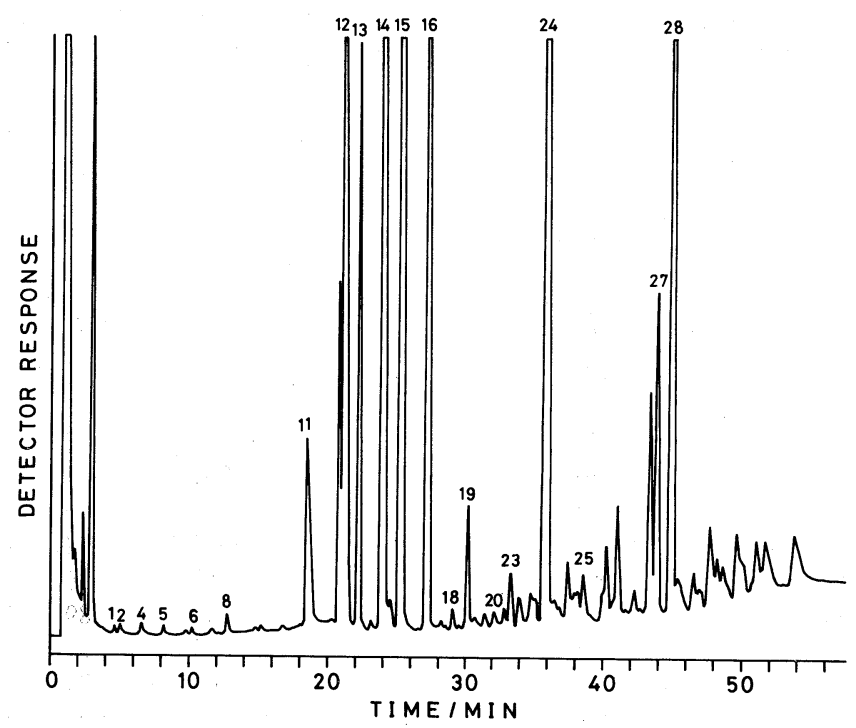

FIG. 2. Gas Chromatogram of Volatile Components in Fresh Swine Faeces (Sample No. 1).

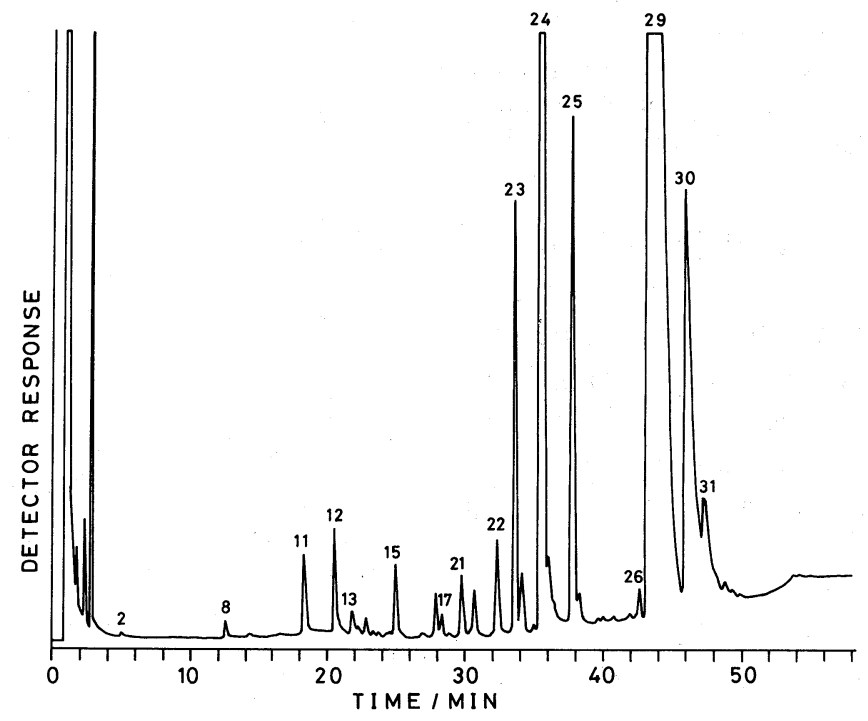

Fig. 3. Gas Chromatogram of Volatile Components in Fresh Swine Urine (Sample No. 3).

is due to ammonia concentration. Several workers have described identification of many amines, ${ }^{8,9,30}$ ) but in this investigation no amines have been detected except for trimethylamine which was detected without quantification by GC. The amount of trimethylamine was very small compared with ammonia. Therefore, trimethylamine is considered not to affect $\mathrm{pH}$ value.

Typical gas chromatograms of volatile ex- tracts are shown in Figs. 2, 3, 4 and 5, where peaks with the number are referred to the corresponding compounds in Table IV. Generally the gas chromatographic pattern for volatiles in faeces of older pigs is simpler than that for volatiles in faeces of younger pigs. ${ }^{28)}$ Peaks without a number are due to odorless compounds or unidentified compounds or insignificant compounds which are barely detected in most cases. The number of peaks in 




FIG. 4. Gas Chromatogram of Volatile Components in Rotten Swine Urine (Sample No. 7).

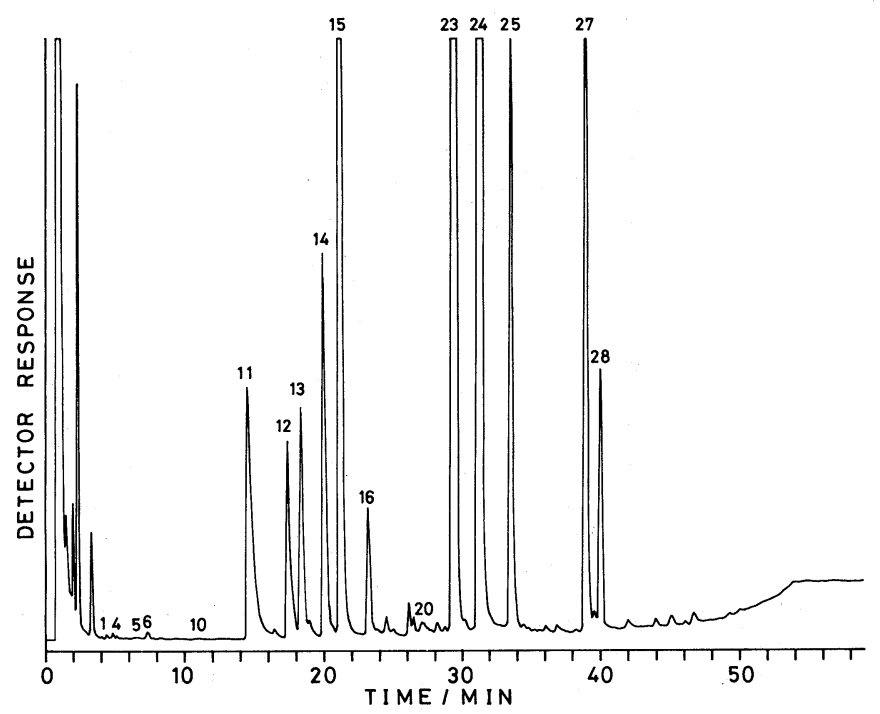

FIG. 5. Gas Chromatogram of Volatile Components in a Rotten Mixture of Swine Faeces and Urine (Sample No. 11).

Fig. 3 is more than that in Fig. 4. Apparently, unstable compounds contained in fresh urine disappear during digestion.

Results of identification and quantification are shown in Table IV with odor threshold values described in the literature. ${ }^{31)}$ Although many other components were identified by GC/MS, they were neglected in Table IV. Because they seemed not to be common components or not to be important for odor. A search of mass spectra was performed with the assistance of a computer-assisted library search system. ${ }^{32)}$

\section{Alcohols}

Aliphatic alcohols have been detected in fresh faeces, while, except for propanol, they have not been present in fresh urine. Rotten urine and rotten mixtures of urine and faeces have contained several alcohols. These alco- 
Table IV. Analytical Results of Odorous Components

\begin{tabular}{|c|c|c|c|c|c|c|}
\hline \multirow{2}{*}{$\begin{array}{l}\text { Peak } \\
\text { No. }\end{array}$} & \multirow{2}{*}{ Compound } & \multicolumn{4}{|c|}{ Concentration $^{a}(\mu \mathrm{g} / \mathrm{g})$} & \multirow{2}{*}{$\begin{array}{l}\text { Odor } \\
\text { threshold }^{b}\end{array}$} \\
\hline & & Fresh faeces & Fresh urine & Rotten urine & Rotten mixtures & \\
\hline 1 & 1-Methylethanol & 0.08 & ND & 0.98 & 0.41 & $3.20(31)$ \\
\hline 2 & Propanol & 0.10 & 0.12 & ND & ND & $<0.03(31)$ \\
\hline 3 & 2-Methoxyethanol & ND & ND & 0.14 & ND & \\
\hline 4 & 2-Methylpropanol & 0.13 & ND & ND & 0.13 & $0.68(31)$ \\
\hline 5 & Butanol & 0.13 & ND & ND & 0.06 & $0.30(31)$ \\
\hline 6 & 3-Methylbutanol & 0.08 & ND & 0.02 & 0.10 & \\
\hline 7 & Pentanol & 0.01 & ND & ND & ND & $0.12(31)$ \\
\hline 8 & 3-Hydroxy-2-butanone & 0.75 & 1.32 & ND & ND & \\
\hline 9 & 3-Octanol & ND & ND & 0.10 & ND & \\
\hline 10 & 2,3,4-Trithiapentane & ND & ND & ND & 0.05 & $0.0014(39)$ \\
\hline 11 & Acetic acid & 14.8 & 10.2 & 76.5 & 56.9 & $0.21(31)$ \\
\hline 12 & Propanoic acid & 31.6 & 0.43 & 3.24 & 13.7 & $0.0084(31)$ \\
\hline 13 & 2-Methylpropanoic acid & 10.3 & 0.68 & 1.59 & 12.5 & $0.0070(31)$ \\
\hline 14 & Butanoic acid & 33.9 & 0.41 & 5.32 & 20.5 & $0.00070(31)$ \\
\hline 15 & 3-Methylbutanoic acid & 36.1 & 2.49 & 11.4 & 45.6 & $0.00044(31)$ \\
\hline 16 & Pentanoic acid & 26.6 & 0.20 & 0.97 & 3.60 & $0.00062(31)$ \\
\hline 17 & 2-Methyl-2-butenoic acid & ND & 1.01 & ND & ND & \\
\hline 18 & 4-Methylpentanoic acid & 0.38 & ND & ND & ND & \\
\hline 19 & Hexanoic acid & 1.20 & ND & ND & ND & \\
\hline 20 & 2-Phenylethanol & 0.24 & ND & ND & 0.20 & \\
\hline 21 & $o$-Methoxyphenol & ND & 3.67 & 2.69 & ND & \\
\hline 22 & $\begin{array}{l}\text { 3-Hydroxy-2-methyl-4- } \\
\text { pyrone }\end{array}$ & ND & 1.65 & 1.18 & ND & \\
\hline 23 & Phenol & 0.50 & 9.13 & 15.3 & 67.1 & $0.059(31)$ \\
\hline 24 & $p$-Cresol & 28.5 & 113 & 130 & 85.0 & $0.0019(31)$ \\
\hline 25 & $p$-Ethylphenol & 0.48 & 11.2 & 12.6 & 6.68 & \\
\hline 26 & $p$-Methoxyphenol & ND & 1.35 & 1.04 & ND & \\
\hline 27 & Indole & 3.39 & ND & 1.69 & 7.99 & \\
\hline 28 & 3-Methylindole & 8.35 & ND & ND & 2.82 & $\begin{array}{l}0.000000075 \\
\text { (31) }\end{array}$ \\
\hline 29 & Benzoic acid & ND & 89.0 & 5.45 & ND & \\
\hline 30 & Phenylacetic acid & ND & 16.2 & 3.03 & ND & \\
\hline 31 & 3-Phenylpropanoic acid & ND & 5.08 & 1.28 & ND & \\
\hline
\end{tabular}

a Concentrations of acetic acid were corrected with recovery coefficient $(79 \%)$. All concentrations are averaged ones. ND means not to be detected.

b Threshold values are concentrations $(\mathrm{ppm})$ in atmosphere. The number in parenthesis corresponds to the reference number in the literature cited.

hols have already been reported by some investigators. $5,7,9,10,23)$ 2-Methoxyethanol was detected only in rotten urine. A similar compound, 2-ethoxy-1-propanol, has been identified in the atmosphere of swine buildings. ${ }^{33)} \mathrm{It}$ is interesting that the amount of 1-methylethanol has been larger in rotten manures than in fresh faeces. Most alcohols in rotten mixtures of urine and faeces seem to have come from faeces. 2-Phenylethanol which has a rather favorable odor has been detected very often in swine manure. This compound which is considered to be produced by microbial degradation of protein ${ }^{34)}$ does not play an important role in odor.

\section{Carbonyl compounds}

Aliphatic ketones are often detected, although they have not been described in Table IV because they were only trace components. Usually concentrations of 2-alkanones are very low and become lower in faeces with the 
growth of the pig. ${ }^{28)}$ Since pigs in this experiment were between 4 and 5 months old, it is reasonable that 2-alkanones were barely detected. Aldehydes have not been determined in this study, though several determinations have been reported. ${ }^{7,35)}$ A few workers ${ }^{5,36)}$ have reported the presence of higher aldehydes such as $\mathrm{C}_{10} \sim \mathrm{C}_{18}$ and their important role in malodor, but those aldehydes are not considered as significant malodorous components because of their odor quality which is rather sweet. In this investigation, 3-hydroxy-2-butanone was detected in faeces and fresh urine and disappeared during digestion. 3-Hydroxy-2butanone which has a putrid odor is one of the most important compounds, although Burnett $^{37)}$ who detected the compound in poultry manure has described it as only a minor contributor to malodor. Only a few reports ${ }^{33,38)}$ have shown the detection of this compound in swine manure.

\section{Sulfur-containing compounds}

2,3,4-Trithiapentane (dimethyl trisulfide) was detected in rotten mixtures of faeces and urine. This compound is malodorous and its odor threshold is very low. ${ }^{39)}$ It seems to occur during digestion. This compound and a similar compound, 2,3,4,5-tetrathiahexane (dimethyl tetrasulfide), have been previously detected in swine manure by the authors. ${ }^{17,33)}$ Many odorous sulfur-containing compounds are known to be present in swine manure, ${ }^{7,9,12,40,41)}$ but in this investigation these compounds were not trapped because of insufficient cooling of the receiver. Dimethyl sulfone has been detected at relatively high concentrations in all samples, although it is not listed in Table IV because of its odorlessness. The mechanism by which dimethyl sulfone is produced remains unknown. Recently it has been proposed that hydrogen sulfide, which is produced in large amounts from liquid swine manure, ${ }^{7,42)}$ is deodorized by chemical reaction in anaerobic conditions. ${ }^{43}$ Banwart and Bremner ${ }^{44,45)}$ have suggested that many sulfur-containing compounds are present in swine manure at low concentrations.

\section{Fatty acids}

Only trace amounts of fatty acids were contained in fresh urine, but those amounts were increased several times by digestion, while faeces included much fatty acids originally. When observed concentrations of fatty acids in rotten mixtures of faeces and urine were compared with values calculated from the addition of each concentration in fresh faeces and rotten urine, it was shown that large amounts of fatty acids were produced during digestion by mixing faeces and urine. Namely, calculated values for acetic, propanoic, 2methylpropanoic, butanoic, 3-methylbutanoic, and pentanoic acids are 63.5, 9.20, $3.42,11.3,16.6$ and $6.36 \mu / \mathrm{g}$, respectively. Concentrations observed for 2-methylpropanoic and 3-methylbutanoic acids were larger than the values calculated. Acetic acid is the most abundant in fresh urine, rotten urine, and rotten mixtures of faeces and urine. This observation agrees with other reports. ${ }^{29,30)}$ The observation that acetic acid shows the highest concentration among fatty acids in pig slurry is consistent with the results of Burnett. ${ }^{37)}$ It was reported that the decreasing order of concentration was acetic acid $>$ propanoic acid $>$ butanoic acid. But the order has not been observed in this investigation, where the decreasing order of concentration was acetic acid $>$ 3-methylbutanoic acid > butanoic acid. 4Methylpentanoic acid and hexanoic acid containing six carbon atoms were at low concentrations in faeces and were not detected in fresh urine, rotten urine, and rotten mixtures of urine and faeces in this investigation. It is interesting that a volatile unsaturated fatty acid, 2-methyl-2-butenoic acid, has been detected in fresh urine only. The role of this acid is unknown. It is noteworthy that distribution of fatty acids in faeces is very different from that in rotten manure. It has been reported that a large part of malodor in swine manure is due to fatty acids. ${ }^{16,23)}$ The relationship between total concentration of volatile fatty acids and odor concentration of air in pig houses has been observed. ${ }^{9}{ }^{9}$ However, the odor threshold of each volatile fatty acid is generally 
different from each other. High concentrations of acetic acid or propanoic acid is not important for malodor. Particularly, odor thresholds of butanoic acid, 3-methylbutanoic acid, and pentanoic acid are a few dozens times or several hundreds times lower than that of acetic acid. ${ }^{31)}$ Therefore, butanoic acid, 3-methylbutanoic acid, and pentanoic acid are the most important for odor among the volatile fatty acids. From this viewpoint, the results in this investigation are roughly consistent with the results of Stevens and Cornforth. ${ }^{46)}$ Concentration of volatile fatty acids is low under aerobic conditions and they become higher under anaerobic conditions. ${ }^{47)}$ Furthermore, volatile fatty acids decrease when methane fermentation occurs. ${ }^{48)}$

Volatile fatty acids are formed from fiber and protein by microbial degradation. ${ }^{29)}$ According to the report of Allison, ${ }^{49)}$ 2methylpropanoic acid, 3-methylbutanoic acid, and 2-methylbutanoic acid are produced from valine, leucine, and isoleucine, respectively. 2Methylbutanoic acid is not common in swine manure, although there are a few reports of its detection. ${ }^{5,10,16,18)}$ Although Sakimoto and Miyazaki $^{36)}$ have identified higher saturated and unsaturated fatty acids such as $\mathrm{C}_{12}, \mathrm{C}_{14}$, $\mathrm{C}_{16}$, and $\mathrm{C}_{18}$ acids, it seems to be unlikely that those acids are important malodorous compounds. It is noteworthy that higher fatty acids which are odorless are distilled by steam distillation.

\section{Aromatic carboxylic acids}

Large amounts of benzoic acid, phenylacetic acid, and 3-phenylpropanoic acid were contained in fresh urine. While, these acids were not detected in faeces. Furthermore, concentrations of these acids in urine decreased rapidly with digestion. These results have been manifested first by this investigation, although identification of aromatic carboxylic acids has been carried out by several workers. ${ }^{10,16,33,36,50)}$ Benzoic acid is not an important odorous compound because of the weak odor. Phenylacetic acid and 3-phenylpropanoic acid are malodorous and important. It is well-known that phenylacetic acid is produced via 2-phenylethylamine and phenylacetaldehyde from phenylalanine. ${ }^{34)}$ Benzoic acid is formed via 3-phenylpropenoic acid through another pathway from phenylalanine. ${ }^{34)} 3$ Phenylpropanoic acid is a reduction product from 3-phenylpropenoic acid by hydrogenase. ${ }^{34)}$ Since these reactions are carried out in mammalian bodies and metabolic products are excreted in urine, it is reasonable that aromatic carboxylic acids have been detected only in urine. But Spoelstra ${ }^{51)}$ has described that 3-phenylpropanoic acid is produced rapidly by microorganisms ${ }^{52)}$ from $3-\left(4^{\prime}-\right.$ hydroxyphenyl)propanoic acid, which is an intermediate in tyrosine metabolism in piggery wastes. Production of aromatic carboxylic acids from phenylalanine by microorganisms is well-known, ${ }^{34)}$ but the pathways seem not to be important in the swine manure used in this investigation because no aromatic carboxylic acids have been detected in fresh faeces and rotten mixtures of faeces and urine. It is noteworthy that these results do not deny the possibility of production of the acids by microorganisms in swine faeces in general. From the results of this investigation, these aromatic carboxylic acids do not play an important role on malodor of rotten manure, although odor of the acids is important in fresh urine.

\section{Phenols}

$p$-Cresol was contained in all samples at the highest concentration. Phenols are not contained originally in urine, since they are excreted as glucuronides in urine. Glucuronides are hydrolyzed rapidly to produce phenol, $p$ cresol, and $p$-ethylphenol by enzymes from microorganisms in swine faeces. ${ }^{53)}$ It has already been shown that microorganisms in the intestine of pigs produce enzymes with high activity such as $\beta$-glucuronidase. ${ }^{54,55)}$ Results of this investigation have shown that enzymic degradation of glucuronides into phenols is accomplished within several hours after excretion of urine, since increases of $p$-cresol and $p$-ethylphenol in rotten urine have been fairly 
small. These observations are consistent with the results of Spoelstra. ${ }^{53)}$ High concentration of phenols in fresh urine has shown that fresh urine used in the experiments had already been contaminated with trace amount of faeces. In fact, it has been impossible to collect urine without microbial contamination and without contact with faeces. Phenol might be produced from other precursors, since the concentration in rotten mixtures of faeces and urine was extraordinarily high. The origins of these phenols are considered as follows. At first tyrosine is decomposed in the intestine of pigs to produce phenol, $p$-cresol, and $p$-ethylphenol. ${ }^{56)}$ These phenols taken from intestinal membrane are detoxified with glucuronic acid or sulfuric acid and excreted in urine. ${ }^{34)}$ While, production of these phenols from tyrosine by microorganisms has been reported, ${ }^{57,58)}$ Spoelstra has shown possible pathways in piggery waste or faeces for production of several phenols in model experiments using tyrosine. ${ }^{51)}$ 2-Methoxyphenol and 4-methoxyphenol were detected in urine only. These compounds have been detected in most experiments carried out by the authors. Probably the two methoxyphenols might be produced in metabolism of phenylalanine or tyrosine where catechol and hydroquinone are intermediate products. ${ }^{34)}$ All phenols are odorous and very important.

\section{Indoles}

3-Methylindole (skatole) was contained in faeces only and decreased slowly during digestion while indole was absent in fresh urine and was produced only a little after digestion. Also, indole increased greatly in rotten mixtures of faeces and urine, compared with the concentration of indole in fresh faeces. This fact is in accordance with the result of previous experiments. ${ }^{18,53)}$ The result that 3-methylindole in fresh faeces is more abundant than indole has been consistent with results in the literature. ${ }^{27)}$ Concentrations of indole and 3methylindole in this investigation are comparable to the results of other investigators. $^{27,53)}$ It is well-known that indole and 3- methylindole are produced from tryptophan by intestinal bacteria and excreted in faeces. Indole and 3-methylindole are important odorous compounds, since the odor threshold of 3 -methylindole is very low. ${ }^{31)}$

The total amount of odorous compounds in rotten mixtures of faeces and urine was the largest among all samples.

Schaefer has gotten the highest correlation between odor strength and concentration of $p$ cresol. ${ }^{4)}$ Also, Schaefer et al. ${ }^{59)}$ have reported that the odor from mixing phenol, $p$-cresol, indole, 3-methylindole, butanoic acid, and 2,3butanedione is the most similar to the odor of piggery wastes in sensory tests. According to experiments by Yasuhara, ${ }^{60)}$ the odor from mixing 2-methylpropanoic acid, butanoic acid, 3-methylbutanoic acid, pentanoic acid, $p$ cresol, indole, 3-methylindole, dimethyl sulfide, dimethyl disulfide, butanol and 3-methylbutanol is the most similar to the odor of the extracts from swine faeces. These observations agree with the results of this investigation which have shown that the significant odorous compounds are alcohols, 3-hydroxy-2-butanone, fatty acids, aromatic carboxylic acids, phenols, and indoles. Subjective sensory tests carried out by two panels have shown that the odor qualities of fresh faeces, fresh urine, rotten urine, and rotten mixtures of faeces and urine are clearly different from each other. A part of the difference is explained by differences of the odorous components described in this article.

\section{REFERENCES}

1) A. Yasuhara, Health Care, 24, 639 (1982).

2) M. Tsuji, T. Yamazaki, T. Okuno and K. Shintani, Bull. Hyogo Prefect. Inst. Environ. Stud., 10, 51 (1978).

3) A. Yasuhara, Bunseki, 792 (1981).

4) J. Schaefer, Agric. Environ., 3, 121 (1977).

5) M. Yoronaga and H. Tanaka, Bull. Natl. Inst. Anim. Ind., 19, 127 (1979).

6) D. L. Day, E. L. Hansen and S. Anderson, Trans. Am. Soc. Agric. Eng., 8, 118 (1965).

7) J. A. Merkel, T. E. Hazen and J. R. Miner, Trans. Am. Soc. Agric. Eng., 12, 310 (1969).

8) J. R. Miner and T. E. Hazen, Trans. Am. Soc. Agric. 
Eng., 12, 772 (1969).

9) C. L. Barth and L. B. Polkowski, Trans. Am. Soc. Agric. Eng., 17, 737 (1974).

10) P. Schreier, VDI-Ber., 226, 127 (1975).

11) F. Lunn and J. Van De Vyver, Agric. Environ., 3, 159 (1977).

12) J. Hartung and H. G. Hilliger, Agric. Environ., 3, 139 (1977).

13) L. F. Elliott, J. W. Doran and T. A. Travis, Trans. Am. Soc. Agric. Eng., 21, 130 (1978).

14) E. G. Hammond, C. Fedler and G. Junk, Trans. Am. Soc. Agric. Eng., 22, 1186 (1979).

15) E. G. Hammond, C. Fedler and R. J. Smith, Agric. Environ., 6, 395 (1981).

16) A. Yasuhara and K. Fuwa, Bull. Chem. Soc. Jpn., 50, 731 (1977)

17) A. Yasuhara and K. Fuwa, Bull. Chem. Soc. Jpn., 50, 3029 (1977).

18) A. Yasuhara and K. Fuwa, Bull. Chem. Soc. Jpn., 52, 114 (1979).

19) A. Yasuhara and K. Fuwa, Agric. Biol. Chem., 43, 313 (1979).

20) A. Yasuhara, H. Shiraishi, M. Tsuji and T. Okuno, Environ. Sci. Technol., 15, 570 (1981).

21) A. Yasuhara and K. Fuwa, Agric. Biol. Chem., 46, 1761 (1981).

22) A. Yasuhara and K. Fuwa, J. Chromatogr., 281, 225 (1983).

23) A. Yasuhara and K. Fuwa, Agric. Biol. Chem., 44, 2379 (1980).

24) M. H. Hiatt, Anal. Chem., 55, 506 (1983).

25) L. F. Elliott and T. A. Travis, Soil Sci. Soc. Am. Proc., 39, 480 (1975).

26) M. T. Yokoyama and J. R. Carlson, Appl. Microbiol., 27, 540 (1974).

27) T. A. Travis and L. F. Elliott, J. Environ. Qual., 6, 407 (1977).

28) A. Yasuhara, K. Fuwa and M. Jimbu, Agric. Biol. Chem., 46, 1381 (1982).

29) S. F. Spoelstra, Neth. J. Agric. Sci., 27, 60 (1979).

30) J. L. Roustan, A. Aumaitre and E. SalmonLegagneur, Agric. Environ., 3, 147 (1977).

31) Y. Shigeta, "Odor Pollution and Deodorization Techniques,” IPC Kogai Boshi Kenkyukai, Tokyo, 1976, pp. 386 424.

32) J. Shindo, A. Yasuhara, H. Ito and T. Mizoguchi, Chem. Lett., 521 (1982).

33) J. R. Miner, M. D. Kelly and A. W. Anderson, Managing Livest. Wastes, Proc. Int. Symp., 3rd 1975, 351 [C. A., 87, 106028b (1977)].

34) The Japanese Biochemical Society (ed.), "Metabolic Map," Tokyo Kagaku Dojin, Tokyo, 1980, pp. $52 \sim 58$.
35). T. Hasegawa, T. Ishiguro, M. Okabayashi, T. Nagashima and Y. Shigeta, J. Odor Contr., 5, No. 25, 15 (1976).

36) M. Sakimoto and A. Miyazaki, "Research Report on Environmental Engineering of Agriculture, Forestry and Fishery," Agency of Agriculture, Forestry and Fishery, 1979, pp. 530 536.

37) W. E. Burnett, Environ. Sci. Technol., 3, 744 (1969).

38) A. Yasuhara, K. Fuwa and M. Jimbu, Agric. Biol. Chem., 48, 111 (1984).

39) F. V. Wilby, J. Air Pollut. Contr. Assoc., 19, 96 (1969)

40) J. Hartung and H. G. Hilliger, Fortschr. Veterinaermed., 28, 54 (1978).

41) A. Yasuhara and K. Fuwa, Chemosphere, 7, 833 (1978).

42) C. L. Barth, D. T. Hill and L. B. Polkowski, Trans. Am. Soc. Agric. Eng., 17, 742 (1974).

43) A. Yasuhara, S. Nagai, K. Fuwa and M. Jimbu, Bull. Chem. Soc. Jpn., 56, 3175 (1983).

44) W. L. Banwart and J. M. Bremner, Soil Biol. Biochem., 7, 359 (1975).

45) W. L. Banwart and J. M. Bremner, J. Environ. Qual., 4, 363 (1975).

46) R. J. Stevens and I. S. Cornforth, J. Sci. Food Agric., 25, 1249 (1974).

47) P. Cooper and I. S. Cornforth, J. Sci. Food Agric., 29, 19 (1978).

48) P. N. Hobson and B. G. Shaw, Water Res., 8, 507 (1974).

49) M. J. Allison, Appl. Environ. Microbiol., 35, 872 (1978)

50) K. Sakata, R. Suemitsu, Y. Toyomaki and Y. Kuwaya, J. Agric. Chem. Soc. Jpn., 51, 115 (1977).

51) S. F. Spoelstra, Appl. Environ. Microbiol., 36, 631 (1978).

52) S. F. Spoelstra, Appl. Environ. Microbiol., 35, 841 (1978).

53) S. F. Spoelstra, J. Sci. Food Agric., 28, 415 (1977).

54) C. A. Marsh, F. Alexander and G. A. Levvy, Nature, 170, 163 (1952).

55) J. Conchie and D. C. MacDonald, Nature, 184, Suppl. No. 16, 1233 (1959).

56) O. M. Bakke, J. Nutr., 98, 209 (1969).

57) H. Enei, H. Matsui, K. Yamashita, S. Okumura and H. Yamada, Agric. Biol. Chem., 36, 1869 (1972).

58) T. C. Chen and R. E. Levin, Appl. Microbiol., 30, 120 (1975).

59) J. Schaefer, J. M. H. Bemelmans and M. C. Ten Noever De Brauw, Landbouwkundig Tijdschrift, 86, 228 (1974).

60) A. Yasuhara, Chemosphere, 9, 587 (1980). 